\title{
A New Method For Determining the Local Environment and Orientation of Individual Sidechains of Membrane-Binding Peptides
}

\author{
M. J. Tucker, ${ }^{\dagger}$ Z. Getahun, ${ }^{\ddagger}$ V. Nanda, ${ }^{\ddagger}$ W. F. DeGrado, ${ }^{\ddagger}$ and F. Gai ${ }^{\dagger}$
}

${ }^{\dagger}$ Department of Chemistry and Department of Biochemistry \& Biophysics, University of Pennsylvania, Philadelphia, PA 19104

\section{Supporting Information}<smiles>N#Cc1ccc(C[C@H](N)C(=O)O)cc1</smiles>

Figure 1. Structure of the nitrile-derivatized amino acid, $\mathrm{Phe}_{\mathrm{CN}}$, used in this study.
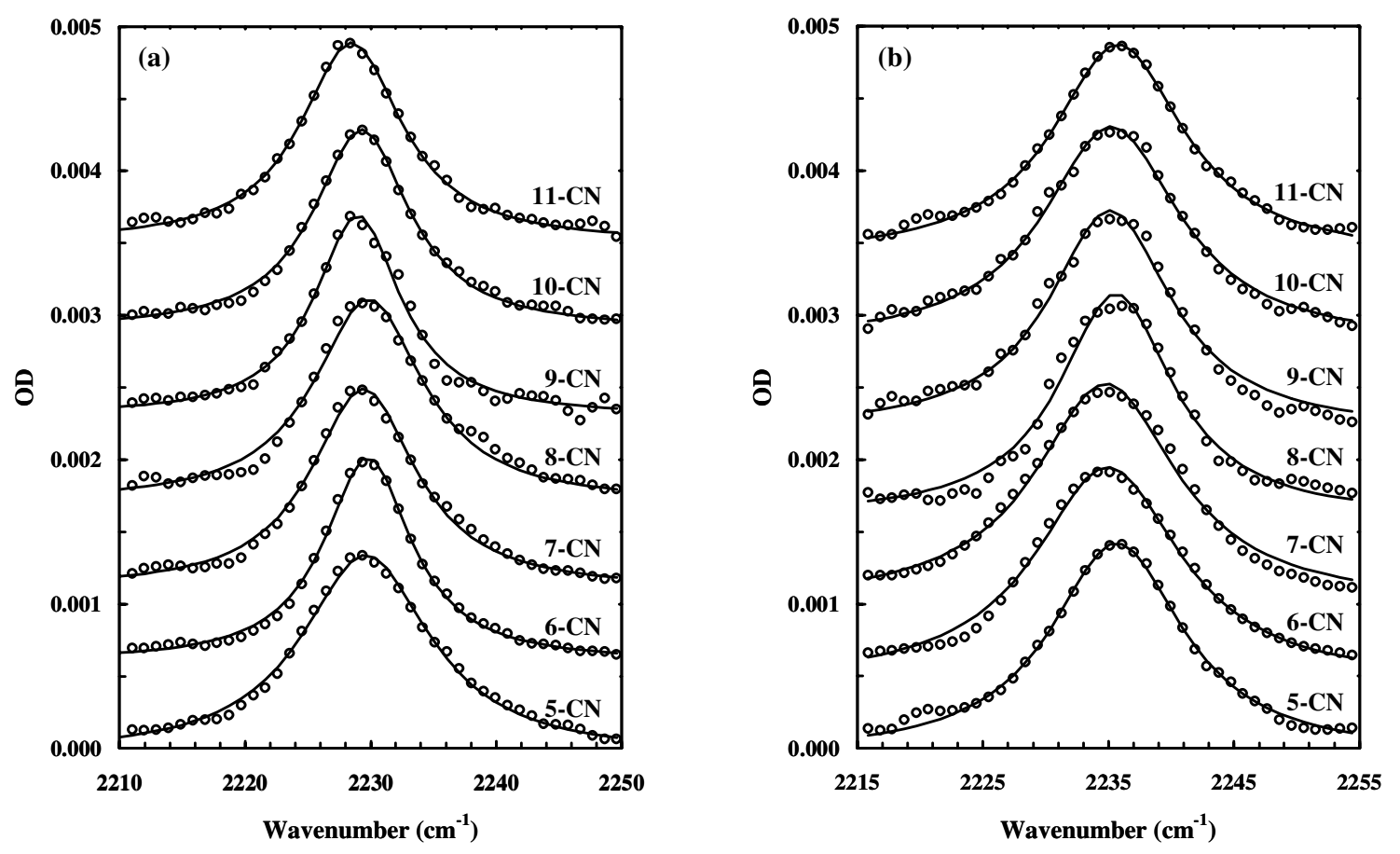

Figure 2. FTIR spectra (in CN stretching region) of MPx-CNy peptides in (a) a zwitterionic lipid bilayer (POPC) and (b) $\mathrm{H}_{2} \mathrm{O}$. A linear background has been subtracted and the data have been offset for clarity. The solid lines are fits to a Lorentzian function. The fitting parameters are given in Table 1. 

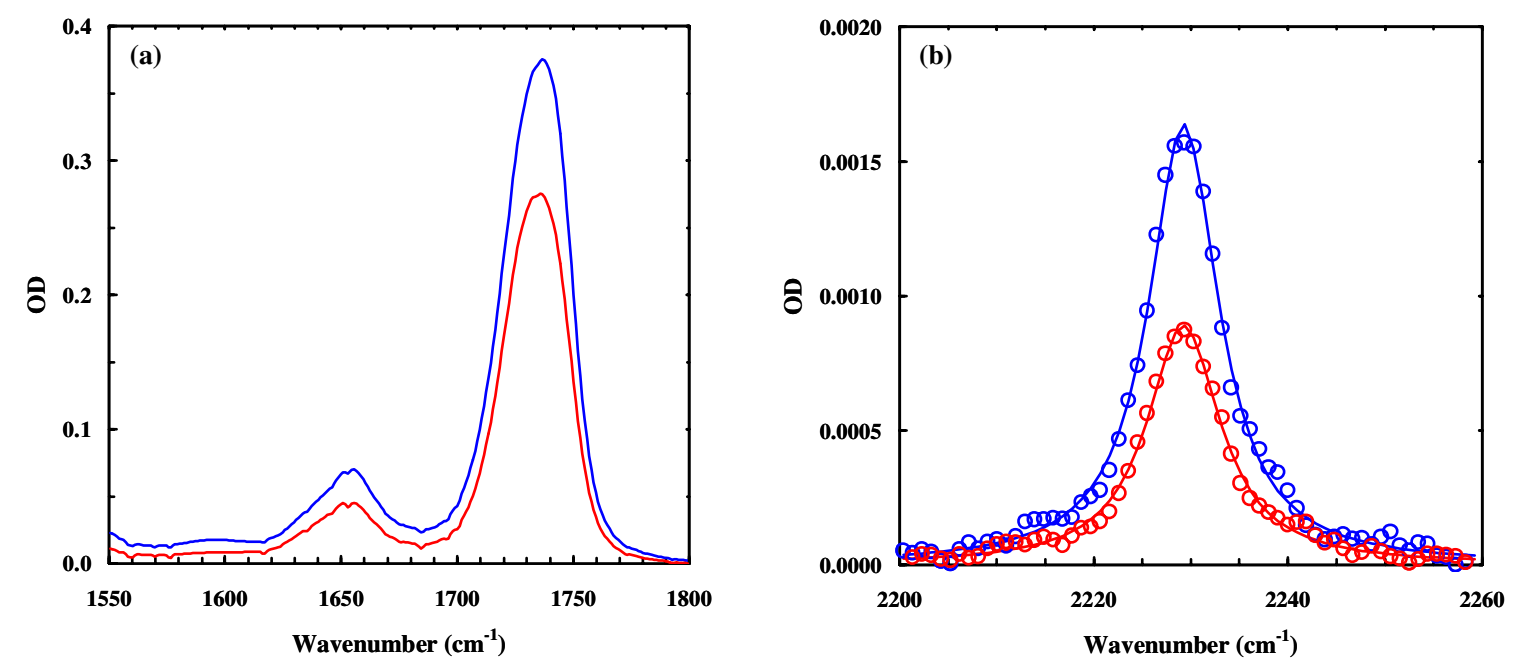

Figure 3. ATR-FTIR spectra of the MPx-CN5 peptide within the lipid bilayer in the amide I region (left) and the $\mathrm{CN}$ stretching region (right) measured with parallel (blue) and perpendicular (red) linearly polarized light. Dichroic ratios used in the angle determination were computed from the integrated areas of the appropriate bands.

\section{Calculation of the Rotamer Angles:}

An ideal fifteen-residue $\alpha$-helix with 3.6 residue/turn was generated and aligned such that its major helical axis was perpendicular to the membrane normal and its hydrophobic side faces the lower layer of the lipids. Positions 5 to 11 were successively mutated to $\mathrm{Phe}_{\mathrm{CN}}$, and built in the trans and gauche ${ }^{-}$rotamer conformations. The projection onto the helical axis and membrane normal axis was used to determine the computed $\theta$ and $\bullet \alpha$ for the two low energy rotamers at each position.

\section{Angle Determination from Polarized ATR-FTIR Spectra:}

The helix angle and the $\mathrm{CN}$ angle were determined from their polarization dependent FTIR spectra by using the method described by Goormaghtigh et al. ${ }^{1}$, specifically the thick film approximation. In the case of helix angle determination, the integrated area of amide I band was used; whereas for CN angle determination the integrated area of the $\mathrm{CN}$ stretching vibration was used. Other parameters used in the calculations are $\alpha=39^{\circ}$ for $\alpha$-helix and $\alpha=0^{\circ}$ for the CN group, where is the angle between the transition dipole moment and the molecular axis of symmetry; $\mathrm{n}_{1}=4$ for the refractive index of $\mathrm{Ge}$ crystal; $\mathrm{n}_{2}=1.43$ for the refractive index of the lipid; and an incident angle of $45^{\circ}$.

In the angle determination of the $\mathrm{CN}$ group with respect to the helix axis, the orientation distribution function of the $\mathrm{CN}$ dipole was calculated using the following equation ${ }^{1}$ :

$\mathrm{S}_{\text {Experiment }}=\mathrm{S}_{\text {Membrane }} \times \mathrm{S}_{\text {Helix }} \times \mathrm{S}_{\mathrm{CN}}$

Where $S_{\text {Experiment }}$ is the orientation distribution function determined from the measured dichroic ratio of the $\mathrm{CN}$ transition, $\mathrm{S}_{\text {Helix }}$ was determined from the dichroic ratio of the amide $\mathrm{I}$ band, and $\mathrm{S}_{\text {Membrane }}$ is the orientation distribution function of the membrane and was assumed to be 1 . The angle between the helix and the nitrile group was then calculated using the following equation:

$\mathrm{S}_{\mathrm{CN}}=\left(3 \cos ^{2} \beta-1\right) / 2$

\footnotetext{
${ }^{1}$ Goormaghtigh, E.; Raussens, V.; Ruysschaert, J. Biochimica et Biophysica Acta 1999, 1422, 105.
} 